Катеринич Максим Дмитриевич, магистрант Иркутского государственного университета, инженер, Иркутский институт химии им. А.Е. Фаворского СО РАН, e-mail: maks.katerinich.1997@mail.ru

Чернышёва Гульнур Набиулловна, к.Х.н., научный сотрудник, Иркутский институт химии им. А.Е. Фаворского СО РАН, ГАЛОГЕНИРОВАНИЕ N-АРИЛСУЛЬФОНИЛ-3-ПОЛИХЛОРМЕТИЛ-2АЗАБИЦИКЛО[2.2.1]ГЕПТ-5-ЕНОВ

Katerinich M.D., Chernysheva G.N.

\title{
HALOGENATION OF N-ARYLSULFONYL-3-POLYCHLOROMETHYL-2- AZABICYCLO[2.2.1]HEPT-5-ENES
}

\begin{abstract}
Аннотация. Продемонстрирован подход к получению новых полигалогенированных Nсульфонилзамещенных производных азанорборнана, представляющих интерес в качестве ценных реагентов и перспективных биологически активных веществ.

Ключевые слова: сульфонилимины, циклопентадиен, азабицикло[2.2.1]гептены, галогенирование, перегруппировка Вагнера-Меервейна.

Abstract. An approach to the preparation of new polyhalogenated $\mathrm{N}$-sulfonylsubstituted azanorbornane derivatives, which are of interest as valuable reagents and promising biologically active substances, has been demonstrated.
\end{abstract}

Keywords: sulfonylimines, cyclopentadiene, azabicyclo[2.2.1]heptenes, halogenation, Wagner-Meerwein rearrangement.

Замещенные производные 2-азабицикло[2.2.1]гепт-5-енов представляют значительный интерес для исследования их биологической активности и для последующих превращений на пути получения ряда фрармакофорных $N$ гетероциклических производных [1], замещенных производных мочевины и тиомочевины [2], а также сопряженных полимерных систем, содержащих пирролиновые фррагменты в структуре [3]. Можно отметить, что сведения по превращениям, протекающим с участием кратной связи 2-азабицикло[2.2.1]гепт-5енов, ограничены. Таким образом, актуальность развития химии этих соединений не вызывает сомнений.

С целью получения новых представителей замещенных азабициклогептанов, перспективных для последующих исследований, в настоящей работе были проведены реакции арилсульфонилиминов хлораля и фенилдихлорацетальдегида 1 с циклопентадиеном, с получением ряда азабициклогептенов 2, которые в дальнейшем галогенировали бромом и хлором (схема 1). 
Схема 1

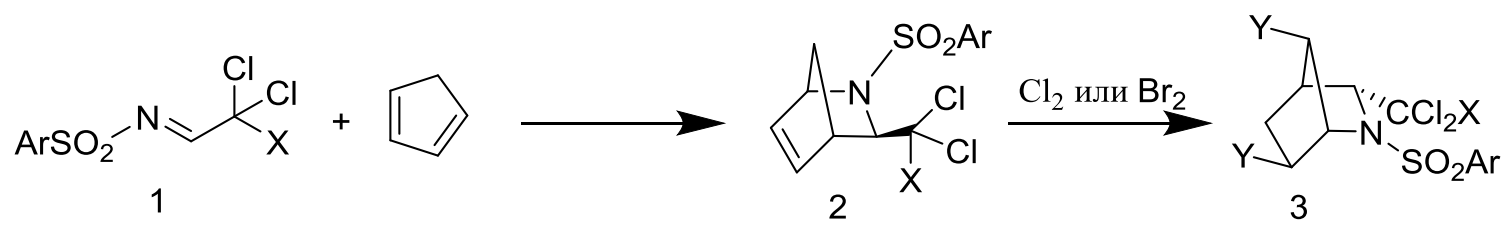

$\mathrm{Ar}=4-\mathrm{ClC}_{6} \mathrm{H}_{4}, 4-\mathrm{MeC}_{6} \mathrm{H}_{4} \mathrm{X}=\mathrm{Cl}, \mathrm{Ph}, \mathrm{Y}=\mathrm{Cl}, \mathrm{Br}$

Установлено, что при галогенировании соединений 2 в хлороформе или трихлорэтилене происходит образование 6,7-дигалогензамещенных производных 3 соответственно с выходом до 75\%, тогда как классические продукты присоединения галогена к кратной связи выделены не были. Можно предположить, что первоначально образующийся в результате электрофильного присоединения галогена мостиковый катион претерпевает перегруппировку типа ВагнераМеервейна.

Строение синтезированных ранее неизвестных продуктов галогенирования 3 доказано методом РСА и изучено с помощью ЯМР спектроскопии.

\section{ЛИТЕРАТУРА}

1. Rearrangement of 2-azanorbornenes to tetrahydrocyclopenta[c]pyridines under the action of activated alkynes - A short pathway for construction of the altemicidin core / D. K. Nasirova, A. V. Malkova, K. B. Polyanskii, K. Yu. Yankina, P. N.-A. Amoyaw, I.A. Kolesnik, A. V. Kletskov, I. A. Godovikov, E. V. Nikitina, F. I. Zubkov // Tetrahedron letters. - 2017. - Vol. 58. - P. 4384-4387.

2. Bowers, A. M. Synthesis of highly substituted ureas and thioureas through 1,3-diaza-Claisen rearrangements / A. M. Bowers, J. S. Madalengoitia // Tetrahedron letters. - 2005. - Vol. 46. - P. 2869-2872.

3. Synthesis of a poly(2-azanorbornene) with a high degree of cis-TTstereoregularity and a regular secondary solution structure / E. Rossegger, L. Olah, R. Fischer, P. Kaschnitz, O. Varga, M. Kallay, G. Scheipl, F. Stelzer, F. Wiesbrock // Polym. Chem. - 2012. - Vol. 3. - P. 2760-2767. 